\title{
Glucose and the injured brain-monitored in the neurointensive care unit
}

\section{Elham Rostami ${ }^{1,2}$ *}

' Department of Neuroscience, Section of Neurosurgery, Uppsala University, Uppsala, Sweden

2 Department of Neuroscience, Karolinska Institutet, Stockholm, Sweden

\section{Edited by:}

Firas H. Kobeissy, University of

Florida, USA

Reviewed by:

Karim A. Sarhane, Johns Hopkins University, USA

Ibrahim Jalloh, University of

Cambridge, UK

${ }^{*}$ Correspondence:

Elham Rostami, Department of Neuroscience, Section of

Neurosurgery, Uppsala University,

SE-751 85 Uppsala, Sweden

e-mail: elham.rostami@neuro.uu.se
Brain has a continuous demand for energy that is met by oxidative metabolism of oxygen and glucose. This demand is compromised in the injured brain and if the inadequate supply persists it will lead to permanent tissue damage. Zero values of cerebral glucose have been associated with infarction and poor neurological outcome. Furthermore, hyperglycemia is common in patients with neurological insults and associated with poor outcome. Intensive insulin therapy (IIT) to control blood glucose has been suggested and used in neurointensive care with conflicting results. This review covers the studies reporting on monitoring of cerebral glucose with microdialysis in patients with traumatic brain injury (TBI), subarachnoid hemorrhage (SAH) and ischemic stroke. Studies investigating IIT are also discussed. Available data suggest that low cerebral glucose in patients with TBI and SAH provides valuable information on development of secondary ischemia and has been correlated with worse outcome. There is also indication that the location of the catheter is important for correlation between plasma and brain glucose. In conclusion considering catheter location, monitoring of brain glucose in the neurointensive care not only provides information on imminent secondary ischemia it also reveals the effect of peripheral treatment on the injured brain.

Keywords: glucose, microdialysis, subarachnoid hemorrhage, Traumatic brain injury, intensive insulin therapy, hyperglycemia, neurocritical care, neuromonitoring

\section{IMPORTANCE OF GLUCOSE MONITORING IN NEUROINTENSIVE CARE}

The development of neurointensive care (NIC) has had a huge impact on improving outcome and reducing mortality in patients with critical neurological conditions (1-4). This NIC includes mainly care for patients with traumatic brain injury (TBI), subarachnoid hemorrhage (SAH), intracranial hemorrhage, spinal cord injury, and acute ischemic stroke. The acute injured brain is characterized by a primary and a secondary injury. Primary brain injury is the acute insult to the brain that can be ischemia, hemorrhage, or trauma among others and is irreversible.

The different types of primary injuries trigger secondary injury processes such as posttraumatic ischemia, energy failure, excitotoxicity, mitochondrial failure, oxidative stress and release of free radicals, secondary cerebral swelling, and inflammation $(5,6)$.

Ischemia plays a major role in the pathology of injured brain and low cerebral glucose values are detected in ischemia.

The injured brain might also be subjected to secondary clinical insults, e.g., high intracranial pressure, hypoxia, hyperglycemia, and hypoglycemia. Hyperglycemia is a common secondary insult in TBI, SAH, and acute ischemic stroke and has repeatedly been associated with poor neurological outcome. A great challenge for the treatment of patients with acute brain injury in the NIC unit is to detect early signs of secondary injuries in order to prevent further advancement and deterioration of the brain tissue. Microdialysis is a widely used technique to monitor the metabolic state of the injured brain and detect metabolic crises defined as low glucose and high lactate/pyruvate ratio (7-9). Monitoring of brain glucose has become even more important due to the increasing interest in controlling blood glucose within defined limits.

Two landmark studies showed that tight glucose control in critically ill surgical patients, aiming for blood glucose in the range $4.4-6.1 \mathrm{mmol} / \mathrm{l}$, reduced mortality and morbidity $(10,11)$. However, these results were later challenged by Finfer et al., who showed an increase in mortality when intensive glucose control was used to treat hyperglycemia (12).

This review will focus on monitoring of cerebral glucose in the most common diagnoses present in the NIC; TBI, ischemic stroke and $\mathrm{SAH}$. It will also cover clinical studies investigating treatment of hyperglycemia in the NIC.

\section{GLUCOSE AND THE BRAIN}

Brain has a continuous demand for energy that is met by oxidative metabolism of oxygen and glucose. Inadequate supply of oxygen or glucose causes cognitive dysfunction and dependent on the duration and severity there will be a progressive deterioration from coma to persistent brain damage and eventually death.

Glucose is the main substrate used by the brain under normal conditions, glycogen and high-energy phosphate compounds such as phosphocreatine and adenosine phosphates only support neuronal functions for 1-3 min (13). During recent years the astrocyte-neuron lactate shuttle (ANLS) hypothesis has emerged. This hypothesis states that astrocytes produce lactate, which is then 
taken up by the adjacent neurons and used as an alternative energy substrate (14).

In the normoxic brain more than $95 \%$ of the adenosine triphosphate (ATP) is derived from aerobic glucose oxidation. Each molecule of glucose is oxidized by 6 molecules of oxygen to carbon dioxide and water, yielding 38 molecules of ATP. Under fully aerobic conditions, lactate production accounts for $<4 \%$ of the glucose metabolized (15). However, the anaerobic glycolysis that breaks down glucose to lactate and pyruvate yields only two molecules of ATP for each molecule of glucose (16). The speed of ATP production is dramatically increased compared to oxidative phosphorylation. During complete ischemia glycolysis is upregulated by seven- to eightfold, within $30 \mathrm{~s}$ all the glucose and glycogen are consumed and by $1 \mathrm{~min}$ all $\operatorname{ATP}(17,18)$.

During inadequate oxygen supply each ATP molecule generates a hydrogen ion and coupled with lactate production leads to lactic acidosis. The extent of lactic acid production is dependent on the preischemic levels of glucose and glycogen (19). The intracellular acidosis that is produced is deleterious for the neurons, nevertheless, it is not the lactate in itself that is harmful. Rather the intracellular increase in hydrogen ion concentration is believed to be cytotoxic (20). Interestingly, moderate increase in lactate post ischemia has been suggested to have neuroprotective effect (21).

Hyperglycemia or hypercapnia exacerbates ischemic damage, indicating that low $\mathrm{pH}$ in combination with ischemia and/or reperfusion enhances detrimental processes and cell death (22-24).

Glucose enters the brain through facilitated diffusion via glucose transporters in the blood-brain barrier (BBB). There is a coupling between $\mathrm{BBB}$ glucose transport and cerebral metabolic rate of glucose (25).

Plasma glucose concentrations are normally maintained between 3.0 and $5.6 \mathrm{mM}$, but can vary between 2 and $10 \mathrm{mM}$ or higher in pathological conditions. Within the brain however, cerebrospinal fluid is buffered to the extent that the range within which glucose concentrations vary is much lower and narrower (0.5-2.5 mM).

\section{BRAIN MICRODIALYSIS AND GLUCOSE}

Microdialysis can be used to monitor the metabolic state of almost any tissue and is a widely used technique for monitoring brain energy metabolism during neurointensive care (Figure 1) (8). It was initially used in rodents studying neurotransmitters (26) and later developed to be used in humans to monitor brain metabolic state (27).

A microdialysis catheter forms a "biosensor." A semipermeable membrane with a double-lumen concentric cannula, mimicking a blood capillary, is attached to the microdialysis catheter. The catheter has an inlet and outlet tube. A sterile fluid is perfused through the inlet tube, and chemical substances from the interstitial fluid diffuse across the membrane into the perfusion fluid in the inner cannula. The inner cannula connects to the outlet tube that ends in a vial holder where the fluid, now referred to as dialyzate, is collected.

The recovery of a substance is defined as the concentration of the substance in the dialyzate expressed as a percentage of the concentration in the interstitial fluid, which is usually assumed to be similar to blood. If the semipermeable membrane is long

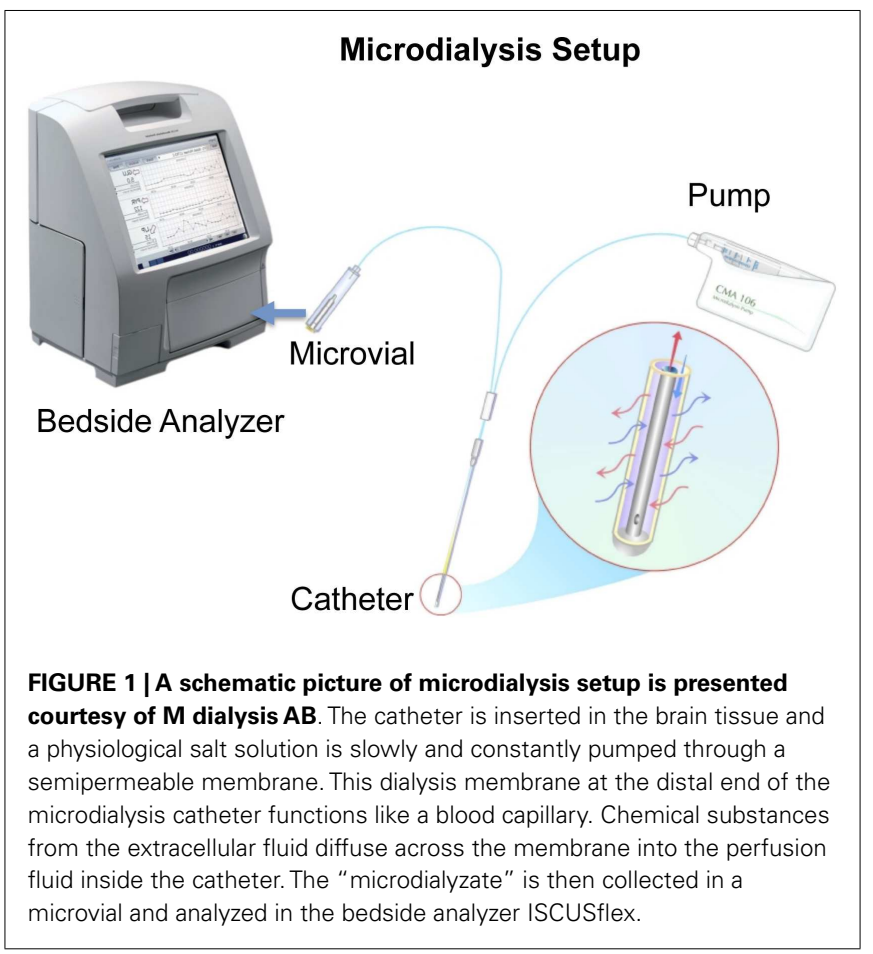

enough and the perfusion flow slow enough, the concentration in the dialyzate membrane will approach the concentration in the interstitial fluid, i.e., recovery will be close to $100 \%$.

The availability of modern analytical techniques has made microdialysis a biosensor capable of monitoring essentially every small and medium sized molecular compound in the interstitial fluid of endogenous as well as exogenous origin.

Normal brain glucose levels have been measured by microdialysis in patients undergoing surgery to treat benign lesions in posterior fossa (28). The cerebral glucose with a perfusion rate of $0.3 \mu \mathrm{l} / \mathrm{min}$ in anesthetized patients was $1.2 \pm 0.6 \mathrm{mmol} / \mathrm{l}$ and awake patients $1.7 \pm 0.9 \mathrm{mmol} / \mathrm{l}$.

Alteration in dialyzate glucose results from several reasons (Table 1):

- Ischemia caused by insufficient blood flow causing decrease levels of tissue glucose and oxygen.

- Hyperemia due to increased blood flow and thereby increased glucose delivery.

- Hyperglycemia due to increased blood glucose that increases the dialyzate glucose.

- Hyper- or hypometabolism this will cause an increase or decrease of glucose uptake into the cells and thereby affect the extracellular glucose available to the microdialysis catheter.

\section{ISCHEMIC STROKE AND GLUCOSE}

Extensive research has been performed on ischemic stroke and a review of these is outside the scope of the current paper. Ischemic infarcts are usually not admitted to the NIC unit and thus do not receive invasive neuromonitoring. This is because they have typically motor or sensory deficits with little or no impairment of 
Table 1 |The table presents conditions that can lead to low or high dialyzate glucose.

\begin{tabular}{ll}
\hline High dialyzate glucose & Low dialyzate glucose \\
\hline $\begin{array}{l}\text { Hyperemia due to increased blood } \\
\text { flow and thereby increased }\end{array}$ & $\begin{array}{l}\text { Ischemia caused by insufficient } \\
\text { blood flow causing decrease } \\
\text { lucose delivery }\end{array}$ \\
$\begin{array}{ll}\text { Hyperglycemia due to increased } \\
\text { blood glucose that increases the }\end{array}$ & $\begin{array}{l}\text { Hypoglycemia due to decreased } \\
\text { dialyzate glucose }\end{array}$ \\
$\begin{array}{l}\text { bypometabolism this will cause a } \\
\text { decose that decreases the }\end{array}$ \\
$\begin{array}{l}\text { Hypermetabolism this will cause } \\
\text { the cells and thereby lead to high } \\
\text { extracellular glucose available to } \\
\text { the microdialysis catheter }\end{array}$
\end{tabular}

consciousness. A group of ischemic stroke patient that do attend the NIC unit are patients with massive or malignant infarcts and thus are the patient group in focus in this review.

Massive hemispheric infarctions constitute $10 \%$ of hemispheric strokes and $5 \%$ of all ischemic strokes and have a mortality rate of 50-80\%, which led to the term malignant infarct $(29,30)$.

Infarcts in these patients are followed by a space occupying brain edema causing malignant midline shift and compression of the basal cisterns on neuroimaging.

Admission hyperglycemia has been shown to be present in more than one-third of patients with acute ischemic stroke and is significantly more common in those with more severe strokes (31).

Several studies both in humans and animals have shown worsening neurological outcome following preischemic hyperglycemia. The first study was performed in monkeys receiving glucose solution before cardiac arrest that exacerbated the neurological and histopathological outcome (22). Several additional studies have repeated these result following global ischemia in monkeys (32), cats $(33)$, and dogs $(34,35)$ showing increased neuronal cell death, neurological dysfunction, and mortality. In rats, preischemic hyperglycemia induced post injury seizure and increased structural damage $(36,37)$.

A systemic review and meta-analysis of the middle cerebral artery (MCA) occlusion model showed that the infarct size of the hyperglycemic animals was $94 \%$ larger than normoglycemic animals (38). However, the relevance of these animal hyperglycemia models to the clinical conditions was questioned.

Several studies have shown that hyperglycemia in patients with acute stroke is associated with poor outcome (39-45). This was a key-contributing factor in generating glucose treatment with insulin therapy. Several randomized clinical studies have evaluated the effect of intensive insulin therapy (IIT) (46-53), they included small number of patients and with no conclusion on the clinical efficiency of IIT. The largest randomized clinical trial was UK Glucose Insulin in Stroke Trial, which enrolled 933 patients and showed no clinical benefit of IIT (48). However, the study has been criticized for several significant weaknesses that cause interpretation difficulties.
In a recent randomized study INSULINFARCT trial, 180 patients with acute stroke were randomized to receive IIT or subcutaneous insulin treatment during the first $24 \mathrm{~h}$ (54). It was shown that IIT in the first $24 \mathrm{~h}$ was associated with larger infarct growth and was not recommended.

There are a few studies that have used microdialysis in patients with ischemic stroke but unfortunately none of them report on dialyzate glucose. Dohmen et al. used cerebral microdialysis in patients with MCA infarction to predict malignant course, but dialyzate glucose was not analyzed (55). Additional studies have used cerebral microdialysis in patients with ischemic stroke but did not report on the dialyzate glucose (55-60).

\section{SUBARACHNOID HEMORRHAGE AND GLUCOSE}

It is estimated that $1-7 \%$ of all strokes are SAH (61). SAH has a huge impact because of the relatively young age of onset and high morbidity and mortality. In aneurysmal SAH, $10-15 \%$ of the patients die before reaching medical care, more than half of the patients die within 2 weeks and the overall mortality is $45 \%$ (62, $63)$. For the survivors observation and monitoring is necessary in order to prevent and detect possible secondary insults.

Cerebral ischemia is one of the devastating secondary insults in SAH (64). This is sometimes reversible, but may also progress to infarction, which is associated with increased mortality and severe disability $(65,66)$. Detection of early perturbation of energy metabolism and cerebral ischemia is highly important in NIC management of SAH patients (67).

In many clinics around the world, cerebral microdialysis is used routinely to detect metabolic disturbances in patients with SAH. Monitoring of brain glucose in these patients has shown to provide essential information. Persson et al. showed that in patients who develop an infarct the glucose values in the MD catheter area decrease to zero and zero values of glucose were detected in patients with unfavorable outcome (68).

The association of zero cerebral glucose value and ischemia in SAH patients was also shown by Schulz et al. They observed significantly lower levels of glucose in patients with severe and complete ischemia when compared with patients without symptoms of ischemia (glucose 0 compared with $2.12 \pm 0.15 \mathrm{mmol} / \mathrm{l}$ ) (69). Decreasing levels of brain glucose and increasing lactate/pyruvate ratio have shown to predict new infarcts in the territory of the microdialysis catheter (70). A low level of glucose $(\leq 0.7 \mathrm{mmol} / \mathrm{l})$ and high $\mathrm{L} / \mathrm{P}$ ratio $(\geq 45)$ was used to define metabolic crises and these were associated with low cerebral perfusion pressure and worse outcome (71).

Delayed cerebral ischemia caused by vasospasm is a common contributing factor to increased morbidity and mortality in SAH. Many methods have been developed to detect and monitor signs of vasospasm including monitoring ischemic metabolites $(72,73)$. Microdialysis catheters were placed in the vascular territory most likely to be affected by vasospasm and it was shown that cerebral glucose was significantly lower in SAH patients presenting signs of clinical vasospasm than in asymptomatic patients (74). Extremely low levels of cerebral glucose were also found in SAH patients with acute ischemic neurologic deficits who developed cerebral infarction (75). Low levels of cerebral glucose have also been associated 
with poor clinical status or neurological deterioration in $\mathrm{SAH}$ patients (76).

The correlation between brain MD glucose levels and plasma glucose concentrations has shown to be heterogeneous with positive, negative, and no correlation at all (77). Plasma glucose concentrations play a major role since hyperglycemia in SAH patients is common and is associated with poor clinical outcome (78-84). One study showed that SAH patients with persistent hyperglycemia are seven times more likely to have poor outcome than patients with normoglycemia (85).

A causal relation between hyperglycemia and poor outcome in SAH patients remains elusive, but it has been suggested that hyperglycemia may exert a detrimental effect by increasing secondary complications such as infection, cerebral ischemia and by facilitating the progression from ischemia to irreversible infarction (86).

These results instigated the need of glucose control and insulin therapy in SAH patients. Several studies have reported on IIT in SAH patients (87-92). One of the major findings is that insulin administration per se decreases the brain glucose independent of serum glucose levels.

Schlenk et al. inserted a microdialysis catheter into the vascular territory of the aneurysm after clipping and treated blood glucose levels above $140 \mathrm{mg} / \mathrm{dl}$ with intravenous insulin. This induced a decrease of cerebral glucose though blood glucose remained normal (93). These results were confirmed in an additional study where hyperglycemia was not related to high cerebral glucose (93). Low cerebral glucose was more frequently observed in symptomatic patients and with unfavorable outcome if combined with hyperglycemia. They concluded that low as well as high levels of brain glucose could occur independently of blood glucose levels in patients with SAH. Also Schmidt et al. reported an association of insulin administration with a relative reduction of interstitial brain glucose concentrations independent of serum glucose levels (94).

The majority of the studies using IIT reported episodes of hypoglycemia. Episodes of hypoglycemia pose additional risks to the brain with compromised metabolism.

Insulin therapy inducing episodes of low glucose $(<4.44 \mathrm{mmol} / \mathrm{l})$ was associated with cerebral infarction, vasospasm, and worse functional outcome 3 months following SAH (92).

Despite several reports on use of IIT in SAH patients there is only one randomized trial where 40 patients receive IIT. This study showed no significant improvement in clinical outcome or the incidence of vasospasm (88).

In conclusion, currently there is no evidence that hyperglycemia in SAH patients should be treated with IIT. This treatment is accompanied by an increase in hypoglycemic episodes, which should raise concerns about the safety of this therapy. Monitoring of cerebral glucose with microdialysis in SAH patients have shown to detect secondary ischemia that could reflect development of vasospasm. It has also been correlated with outcome and thus provides valuable information.

\section{TRAUMATIC BRAIN INJURY AND GLUCOSE}

Traumatic brain injury is the leading cause of death in young adults in industrialized nations and in the population under 35 years, the death rate is 3.5 times that of cancer and heart disease combined
(95). The primary injury initiates metabolic crises, posttraumatic ischemia, and neuronal death $(5,96)$. In addition, the injured brain might also be subjected to secondary insults, e.g., hypoxia, hypercapnia, hypocapnia, hypotension, hyperglycemia, and hypoglycemia. A great challenge for the treatment of TBI patients in the NIC unit is to detect early signs of secondary injuries in order to prevent further advancement and deterioration of the brain tissue. Brain microdialysis is widely used to detect ischemia and metabolic crises in TBI $(8,97)$.

Several studies have reported on increased glycolysis in the acute phase of brain injury (98-100) and low dialyzate glucose levels have been associated with poor outcome $(101,102)$. Hence the importance of adequate glucose supply from systemic circulation to the injured brain. It has been shown that the intracerebral glucose concentration increased significantly during transient episodes of both moderate and pronounced hyperglycemia (103). Increased dialyzate glucose has shown to be associated with high mortality (104). A linear correlation between peripheral glucose and brain glucose was demonstrated in TBI patients (105). However, there were opposing results in a study monitoring both the injured hemisphere and non-injured hemisphere in TBI patients. While the non-injured hemisphere showed a positive correlation with plasma glucose, the injured hemisphere presented a more heterogeneous pattern with no significant correlation to the blood glucose in the first $12 \mathrm{~h}$ of NIC unit (106). This emphasizes the importance of microdialysis catheter placement.

Hyperglycemia is frequently observed in patients with TBI and the degree of hyperglycemia observed can be a predictor of outcome (107-111). As previously discussed, hyperglycemia exacerbates ischemic neurological injury and contributes to poor outcome also in TBI patients. Thus, the effect of insulin therapy has also been studied in TBI patients.

Reducing the plasma glucose by insulin therapy has been shown to decrease cerebral glucose and was associated with brain energy crises in TBI patients. As previously mentioned, Oddo et al. defined brain energy crisis as a cerebral microdialysis glucose $<0.7 \mathrm{mmol} / \mathrm{l}$ with a lactate/pyruvate ratio $>40$. It was shown that insulin administration was associated with brain energy crises, which in turn correlated with increased mortality (100). Vespa et al. also showed decreased dialyzate glucose upon insulin therapy but did not find an effect on mortality or functional outcome (112). A retrospective study compared clinical outcomes before and after implementation of IIT in 228 TBI patients. Although episodes of hypoglycemia were significantly more common in the IIT group the overall mortality was similar in both groups (113).

A randomized controlled trial of 97 patients with severe TBI compared a regimen of IIT (target blood glucose 4.42$6.63 \mathrm{mmol} / \mathrm{l}$ ) versus conventional management (target blood glucose 4.42 and $12.15 \mathrm{mmol} / \mathrm{l})$. The only favorable endpoint associated with the use of IIT was a shorter stay in the NIC unit. No significant differences were observed in rates of mortality and poor functional outcome at 6 months. Meanwhile, the incidence of hypoglycemic events was markedly increased among patients treated with IIT (114). This was confirmed in an additional randomized trial with total of 523 patients including 94 TBI patients. IIT was not associated with improved survival and was associated with increased occurrence of hypoglycemia (115). 
In conclusion, current clinical trials do not show any benefit of tight glucose control with IIT in TBI patients. On the contrary it might increase the incidence of hypoglycemia, exacerbating brain metabolic crises (116). Available data suggest that high as well as low cerebral glucose measured by microdialysis is associated with high mortality. There is an indication that the placement of the catheter is important for correlation between plasma and brain glucose.

\section{CONCLUDING REMARKS}

There is a vast amount of evidence that hyperglycemia is common in patients with TBI, SAH, and ischemic stroke and that it is related to poor outcome. However, no solid evidence exist that tight glycemic control improves outcome in these patients. It might on the contrary lead to hypoglycemic episode with deleterious effect on the injured brain. Monitoring of glucose with microdialysis has proven to predict ischemic infarcts and detect glucose zero values despite normal blood glucose. Zero dialyzate glucose values are associated with poor outcome. These results also emphasize the importance of catheter location to detect and predict brain tissue at risk of developing infarct.

\section{REFERENCES}

1. Elf K, Nilsson P, Enblad P. Outcome after traumatic brain injury improved by an organized secondary insult program and standardized neurointensive care. Crit Care Med (2002) 30:2129-34. doi:10.1097/00003246-200209000-00029

2. Patel HC, Menon DK, Tebbs S, Hawker R, Hutchinson PJ, Kirkpatrick PJ. Specialist neurocritical care and outcome from head injury. Intensive Care Med (2002) 28:547-53. doi:10.1007/s00134-002-1235-4

3. Clayton TJ, Nelson RJ, Manara AR. Reduction in mortality from severe head injury following introduction of a protocol for intensive care management. $\mathrm{Br}$ J Anaesth (2004) 93:761-7. doi:10.1093/bja/aeh249

4. Fakhry SM, Trask AL, Waller MA, Watts DD. Management of brain-injured patients by an evidence-based medicine protocol improves outcomes and decreases hospital charges. J Trauma (2004) 56:492-9; discussion 499-500. doi:10.1097/01.TA.0000115650.07193.66

5. Siesjo BK, Siesjo P. Mechanisms of secondary brain injury. Eur J Anaesthesiol (1996) 13:247-68. doi:10.1097/00003643-199605000-00004

6. Werner C, Engelhard K. Pathophysiology of traumatic brain injury. Br J Anaesth (2007) 99:4-9. doi:10.1093/bja/aem131

7. Bellander BM, Cantais E, Enblad P, Hutchinson P, Nordstrom CH, Robertson $\mathrm{C}$, et al. Consensus meeting on microdialysis in neurointensive care. Intensive Care Med (2004) 30:2166-9. doi:10.1007/s00134-004-2461-8

8. Ungerstedt U, Rostami E. Microdialysis in neurointensive care. Curr Pharm Des (2004) 10:2145-52. doi:10.2174/1381612043384105

9. Hillered L, Persson L, Nilsson P, Ronne-Engstrom E, Enblad P. Continuous monitoring of cerebral metabolism in traumatic brain injury: a focus on cerebral microdialysis. Curr Opin Crit Care (2006) 12:112-8. doi:10.1097/01.ccx. 0000216576.11439.df

10. Van den Berghe G, Wouters P, Weekers F, Verwaest C, Bruyninckx F, Schetz M, et al. Intensive insulin therapy in critically ill patients. N Engl J Med (2001) 345:1359-67. doi:10.1056/NEJMoa011300

11. Van den Berghe G, Wilmer A, Hermans G, Meersseman W, Wouters PJ, Milants I, et al. Intensive insulin therapy in the medical ICU. N Engl J Med (2006) 354:449-61. doi:10.1056/NEJMoa052521

12. Finfer S, Chittock DR, Su SY, Blair D, Foster D, Dhingra V, et al. Intensive versus conventional glucose control in critically ill patients. N Engl J Med (2009) 360:1283-97. doi:10.1056/NEJMoa0810625

13. Siesjo BK. Pathophysiology and treatment of focal cerebral ischemia. Part I: pathophysiology. J Neurosurg (1992) 77:169-84. doi:10.3171/jns.1992.77.2. 0169

14. Pellerin L. Brain energetics (thought needs food). Curr Opin Clin Nutr Metab Care (2008) 11:701-5. doi:10.1097/MCO.0b013e328312c368
15. Erecinska M, Silver IA. ATP and brain function. J Cereb Blood Flow Metab (1989) 9:2-19. doi:10.1038/jcbfm.1989.2

16. Siesjo BK. Mechanisms of ischemic brain damage. Crit Care Med (1988) 16:954-63. doi:10.1097/00003246-198810000-00006

17. Lowry OH, Passonneau JV. The relationships between substrates and enzymes of glycolysis in brain. J Biol Chem (1964) 239:31-42.

18. Gatfield PD, Lowry OH, Schulz DW, Passonneau JV. Regional energy reserves in mouse brain and changes with ischaemia and anaesthesia. J Neurochem (1966) 13:185-95. doi:10.1111/j.1471-4159.1966.tb07512.x

19. Smith ML, Von Hanwehr R, Siesjo BK. Changes in extra- and intracellular $\mathrm{pH}$ in the brain during and following ischemia in hyperglycemic and in moderately hypoglycemic rats. J Cereb Blood Flow Metab (1986) 6:574-83. doi:10.1038/jcbfm.1986.104

20. Nedergaard M, Goldman SA, Desai S, Pulsinelli WA. Acid-induced death in neurons and glia. J Neurosci (1991) 11:2489-97.

21. Berthet C, Lei H, Thevenet J, Gruetter R, Magistretti PJ, Hirt L. Neuroprotective role of lactate after cerebral ischemia. J Cereb Blood Flow Metab (2009) 29:1780-9. doi:10.1038/jcbfm.2009.97

22. Myers RE, Yamaguchi S. Nervous system effects of cardiac arrest in monkeys. Preservation of vision. Arch Neurol (1977) 34:65-74. doi:10.1001/archneur. 1977.00500140019003

23. Katsura K, Kristian T, Smith ML, Siesjo BK. Acidosis induced by hypercapnia exaggerates ischemic brain damage. J Cereb Blood Flow Metab (1994) 14:243-50. doi:10.1038/jcbfm.1994.31

24. Gisselsson L, Smith ML, Siesjo BK. Hyperglycemia and focal brain ischemia. J Cereb Blood Flow Metab (1999) 19:288-97. doi:10.1097/00004647199903000-00007

25. Pelligrino DA, Lamanna JC, Duckrow RB, Bryan RM Jr, Harik SI. Hyperglycemia and blood-brain barrier glucose transport. J Cereb Blood Flow Metab (1992) 12:887-99. doi:10.1038/jcbfm.1992.126

26. Ungerstedt U, Pycock C. Functional correlates of dopamine neurotransmission. Bull Schweiz Akad Med Wiss (1974) 30:44-55.

27. Ungerstedt U. Microdialysis - principles and applications for studies in animals and man. J Intern Med (1991) 230:365-73. doi:10.1111/j.1365-2796.1991. tb00459.x

28. Reinstrup P, Stahl N, Mellergard P, Uski T, Ungerstedt U, Nordstrom CH. Intracerebral microdialysis in clinical practice: baseline values for chemical markers during wakefulness, anesthesia, and neurosurgery. Neurosurgery (2000) 47:701-9; discussion 709-10. doi:10.1227/00006123-200009000-00035

29. Hacke W, Schwab S, Horn M, Spranger M, De Georgia M, Von Kummer R. "Malignant" middle cerebral artery territory infarction: clinical course and prognostic signs. Arch Neurol (1996) 53:309-15. doi:10.1001/archneur.1996. 00550040037012

30. Kasner SE, Demchuk AM, Berrouschot J, Schmutzhard E, Harms L, Verro P, et al. Predictors of fatal brain edema in massive hemispheric ischemic stroke. Stroke (2001) 32:2117-23. doi:10.1161/hs0901.095719

31. Scott JF, Robinson GM, French JM, O'Connell JE, Alberti KG, Gray CS. Prevalence of admission hyperglycaemia across clinical subtypes of acute stroke. Lancet (1999) 353:376-7. doi:10.1016/S0140-6736(05)74948-5

32. Lanier WL, Stangland KJ, Scheithauer BW, Milde JH, Michenfelder JD. The effects of dextrose infusion and head position on neurologic outcome after complete cerebral ischemia in primates: examination of a model. Anesthesiology (1987) 66:39-48. doi:10.1097/00000542-198701000-00008

33. Nakakimura K, Fleischer JE, Drummond JC, Scheller MS, Zornow MH, Grafe MR, et al. Glucose administration before cardiac arrest worsens neurologic outcome in cats. Anesthesiology (1990) 72:1005-11. doi:10.1097/00000542199006000-00010

34. Natale JE, Stante SM, D'Alecy LG. Elevated brain lactate accumulation and increased neurologic deficit are associated with modest hyperglycemia in global brain ischemia. Resuscitation (1990) 19:271-89. doi:10.1016/0300-9572(90) 90107-P

35. Palmon SC, Sieber FE, Brown PR, Koehler RC, Eleff SM, Traystman RJ. Poor hemodynamic and metabolic recovery after global incomplete cerebral ischemia associated with short-term diabetes in dogs. J Cereb Blood Flow Metab (1995) 15:673-80. doi:10.1038/jcbfm.1995.83

36. Pulsinelli WA, Waldman S, Rawlinson D, Plum F. Moderate hyperglycemia augments ischemic brain damage: a neuropathologic study in the rat. Neurology (1982) 32:1239-46. doi:10.1212/WNL.32.11.1239 
37. Warner DS, Todd MM, Dexter F, Ludwig P, McAllister AM. Temporal thresholds for hyperglycemia-augmented ischemic brain damage in rats. Stroke (1995) 26:655-60. doi:10.1161/01.STR.26.4.655

38. MacDougall NJ, Muir KW. Hyperglycaemia and infarct size in animal models of middle cerebral artery occlusion: systematic review and meta-analysis. J Cereb Blood Flow Metab (2011) 31:807-18. doi:10.1038/jcbfm. 2010.210

39. Candelise L, Landi G, Orazio EN, Boccardi E. Prognostic significance of hyperglycemia in acute stroke. Arch Neurol (1985) 42:661-3. doi:10.1001/archneur. 1985.04060070051014

40. Bruno A, Biller J, Adams HP Jr, Clarke WR, Woolson RF, Williams LS, et al. Acute blood glucose level and outcome from ischemic stroke. Trial of ORG 10172 in acute stroke treatment (TOAST) investigators. Neurology (1999) 52:280-4. doi:10.1212/WNL.52.2.280

41. Capes SE, Hunt D, Malmberg K, Pathak P, Gerstein HC. Stress hyperglycemia and prognosis of stroke in nondiabetic and diabetic patients: a systematic overview. Stroke (2001) 32:2426-32. doi:10.1161/hs1001.096194

42. Baird TA, Parsons MW, Phanh T, Butcher KS, Desmond PM, Tress BM, et al. Persistent poststroke hyperglycemia is independently associated with infarct expansion and worse clinical outcome. Stroke (2003) 34:2208-14. doi:10.1161/01.STR.0000085087.41330.FF

43. Diener HC, Lees KR, Lyden P, Grotta J, Davalos A, Davis SM, et al. NXY-059 for the treatment of acute stroke: pooled analysis of the SAINT I and II trials. Stroke (2008) 39:1751-8. doi:10.1161/STROKEAHA.107.503334

44. Fuentes B, Castillo J, San Jose B, Leira R, Serena J, Vivancos J, et al. The prognostic value of capillary glucose levels in acute stroke: the glycemia in acute stroke (GLIAS) study. Stroke (2009) 40:562-8. doi:10.1161/STROKEAHA.108. 519926

45. Kruyt ND, Biessels GJ, Devries JH, Roos YB. Hyperglycemia in acute ischemic stroke: pathophysiology and clinical management. Nat Rev Neurol (2010) 6:145-55. doi:10.1038/nrneurol.2009.231

46. Hamilton MG, Tranmer BI, Auer RN. Insulin reduction of cerebral infarction due to transient focal ischemia. J Neurosurg (1995) 82:262-8. doi:10.3171/jns. 1995.82.2.0262

47. Walters MR, Weir CJ, Lees KR. A randomised, controlled pilot study to investigate the potential benefit of intervention with insulin in hyperglycaemic acute ischaemic stroke patients. Cerebrovasc Dis (2006) 22:116-22. doi:10.1159/000093239

48. Gray CS, Hildreth AJ, Sandercock PA, O’Connell JE, Johnston DE, Cartlidge NE, et al. Glucose-potassium-insulin infusions in the management of post-stroke hyperglycaemia: the UK glucose insulin in stroke trial (GIST-UK). Lancet Neurol (2007) 6:397-406. doi:10.1016/S1474-4422(07)70080-7

49. Bruno A, Kent TA, Coull BM, Shankar RR, Saha C, Becker KJ, et al. Treatment of hyperglycemia in ischemic stroke (THIS): a randomized pilot trial. Stroke (2008) 39:384-9. doi:10.1161/STROKEAHA.107.493544

50. Johnston KC, Hall CE, Kissela BM, Bleck TP, Conaway MR. Glucose regulation in acute stroke patients (GRASP) trial: a randomized pilot trial. Stroke (2009) 40:3804-9. doi:10.1161/STROKEAHA.109.561498

51. Kreisel SH, Berschin UM, Hammes HP, Leweling H, Bertsch T, Hennerici MG, et al. Pragmatic management of hyperglycaemia in acute ischaemic stroke: safety and feasibility of intensive intravenous insulin treatment. Cerebrovasc Dis (2009) 27:167-75. doi:10.1159/000185608

52. McCormick M, Hadley D, McLean JR, Macfarlane JA, Condon B, Muir KW. Randomized, controlled trial of insulin for acute poststroke hyperglycemia. Ann Neurol (2010) 67:570-8. doi:10.1002/ana.21983

53. Staszewski J, Brodacki B, Kotowicz J, Stepien A. Intravenous insulin therapy in the maintenance of strict glycemic control in nondiabetic acute stroke patients with mild hyperglycemia. J Stroke Cerebrovasc Dis (2011) 20:150-4. doi:10.1016/j.jstrokecerebrovasdis.2009.11.013

54. Rosso C, Corvol JC, Pires C, Crozier S, Attal Y, Jacqueminet S, et al. Intensive versus subcutaneous insulin in patients with hyperacute stroke: results from the randomized INSULINFARCT trial. Stroke (2012) 43:2343-9. doi:10.1161/ STROKEAHA.112.657122

55. Dohmen C, Bosche B, Graf R, Reithmeier T, Ernestus RI, Brinker G, et al. Identification and clinical impact of impaired cerebrovascular autoregulation in patients with malignant middle cerebral artery infarction. Stroke (2007) 38:56-61. doi:10.1161/01.STR.0000251642.18522.b6
56. Schneweis S, Grond M, Staub F, Brinker G, Neveling M, Dohmen C, et al. Predictive value of neurochemical monitoring in large middle cerebral artery infarction. Stroke (2001) 32:1863-7. doi:10.1161/01.STR.32.8.1863

57. Bosche B, Dohmen C, Graf R, Neveling M, Staub F, Kracht L, et al. Extracellular concentrations of non-transmitter amino acids in peri-infarct tissue of patients predict malignant middle cerebral artery infarction. Stroke (2003) 34:2908-13. doi:10.1161/01.STR.0000100158.51986.EB

58. Dohmen C, Bosche B, Graf R, Staub F, Kracht L, Sobesky J, et al. Prediction of malignant course in MCA infarction by PET and microdialysis. Stroke (2003) 34:2152-8. doi:10.1161/01.STR.0000083624.74929.32

59. Heiss WD, Dohmen C, Sobesky J, Kracht L, Bosche B, Staub F, et al. Identification of malignant brain edema after hemispheric stroke by PET-imaging and microdialysis. Acta Neurochir Suppl (2003) 86:237-40.

60. Berger C, Kiening K, Schwab S. Neurochemical monitoring of therapeutic effects in large human MCA infarction. Neurocrit Care (2008) 9:352-6. doi:10.1007/s12028-008-9093-8

61. Feigin VL, Lawes CM, Bennett DA, Anderson CS. Stroke epidemiology: a review of population-based studies of incidence, prevalence, and case-fatality in the late 20th century. Lancet Neurol (2003) 2:43-53. doi:10.1016/S1474-4422(03) 00266-7

62. Sarti C, Tuomilehto J, Salomaa V, Sivenius J, Kaarsalo E, Narva EV, et al. Epidemiology of subarachnoid hemorrhage in Finland from 1983 to 1985 . Stroke (1991) 22:848-53. doi:10.1161/01.STR.22.7.848

63. Hop JW, Rinkel GJ, Algra A, Van Gijn J. Case-fatality rates and functional outcome after subarachnoid hemorrhage: a systematic review. Stroke (1997) 28:660-4. doi:10.1161/01.STR.28.3.660

64. Roos YB, De Haan RJ, Beenen LF, Groen RJ, Albrecht KW, Vermeulen M. Complications and outcome in patients with aneurysmal subarachnoid haemorrhage: a prospective hospital based cohort study in the Netherlands. J Neurol Neurosurg Psychiatry (2000) 68:337-41. doi:10.1136/jnnp.68.3.337

65. Rabinstein AA, Friedman JA, Weigand SD, McClelland RL, Fulgham JR, Manno EM, et al. Predictors of cerebral infarction in aneurysmal subarachnoid hemorrhage. Stroke (2004) 35:1862-6. doi:10.1161/01.STR.0000133132. 76983.8e

66. Schmidt JM, Wartenberg KE, Fernandez A, Claassen J, Rincon F, Ostapkovich ND, et al. Frequency and clinical impact of asymptomatic cerebral infarction due to vasospasm after subarachnoid hemorrhage. J Neurosurg (2008) 109:1052-9. doi:10.3171/JNS.2008.109.12.1052

67. Persson L, Enblad P. Neurointensive care of aneurysmal SAH. Acta Neurochir Suppl (1999) 72:73-80.

68. Persson L, Valtysson J, Enblad P, Warme PE, Cesarini K, Lewen A, et al. Neurochemical monitoring using intracerebral microdialysis in patients with subarachnoid hemorrhage. J Neurosurg (1996) 84:606-16. doi:10.3171/jns.1996. 84.4.0606

69. Schulz MK, Wang LP, Tange M, Bjerre P. Cerebral microdialysis monitoring: determination of normal and ischemic cerebral metabolisms in patients with aneurysmal subarachnoid hemorrhage. J Neurosurg (2000) 93:808-14. doi:10.3171/jns.2000.93.5.0808

70. Helbok R, Madineni RC, Schmidt MJ, Kurtz P, Fernandez L, Ko SB, et al. Intracerebral monitoring of silent infarcts after subarachnoid hemorrhage. Neurocrit Care (2011) 14:162-7. doi:10.1007/s12028-010-9472-9

71. Schmidt JM, Ko SB, Helbok R, Kurtz P, Stuart RM, Presciutti M, et al. Cerebral perfusion pressure thresholds for brain tissue hypoxia and metabolic crisis after poor-grade subarachnoid hemorrhage. Stroke (2011) 42:1351-6. doi:10.1161/STROKEAHA.110.596874

72. Janjua N, Mayer SA. Cerebral vasospasm after subarachnoid hemorrhage. Curr Opin Crit Care (2003) 9:113-9. doi:10.1097/00075198-200304000-00006

73. Hanggi D. Monitoring and detection of vasospasm II: EEG and invasive monitoring. Neurocrit Care (2011) 15:318-23. doi:10.1007/s12028-011-9583-y

74. Unterberg AW, Sakowitz OW, Sarrafzadeh AS, Benndorf G, Lanksch WR. Role of bedside microdialysis in the diagnosis of cerebral vasospasm following aneurysmal subarachnoid hemorrhage. J Neurosurg (2001) 94:740-9. doi:10.3171/jns.2001.94.5.0740

75. Sarrafzadeh AS, Sakowitz OW, Kiening KL, Benndorf G, Lanksch WR, Unterberg AW. Bedside microdialysis: a tool to monitor cerebral metabolism in subarachnoid hemorrhage patients? Crit Care Med (2002) 30:1062-70. doi:10.1097/00003246-200205000-00018 
76. Nilsson OG, Brandt L, Ungerstedt U, Saveland H. Bedside detection of brain ischemia using intracerebral microdialysis: subarachnoid hemorrhage and delayed ischemic deterioration. Neurosurgery (1999) 45:1176-84; discussion 1184-5. doi:10.1097/00006123-199911000-00032

77. Zetterling M, Hillered L, Enblad P, Karlsson T, Ronne-Engstrom E. Relation between brain interstitial and systemic glucose concentrations after subarachnoid hemorrhage. J Neurosurg (2011) 115:66-74. doi:10.3171/2011.3. JNS10899

78. Dorhout Mees SM, Van Dijk GW, Algra A, Kempink DR, Rinkel GJ. Glucose levels and outcome after subarachnoid hemorrhage. Neurology (2003) 61:1132-3. doi:10.1212/01.WNL.0000090466.68866.02

79. Badjatia N, Topcuoglu MA, Buonanno FS, Smith EE, Nogueira RG, Rordorf GA, et al. Relationship between hyperglycemia and symptomatic vasospasm after subarachnoid hemorrhage. Crit Care Med (2005) 33:1603-9; quiz 1623. doi:10.1097/01.CCM.0000168054.60538.2B

80. Lanzino G. Plasma glucose levels and outcome after aneurysmal subarachnoid hemorrhage. J Neurosurg (2005) 102:974-5; discussion 975-6. doi:10.3171/jns. 2005.102.6.0974

81. Frontera JA, Fernandez A, Claassen J, Schmidt M, Schumacher HC, Wartenberg $\mathrm{K}$, et al. Hyperglycemia after SAH: predictors, associated complications, and impact on outcome. Stroke (2006) 37:199-203. doi:10.1161/01.STR. 0000194960.73883.0f

82. Kruyt ND, Roos YW, Dorhout Mees SM, Van den Bergh WM, Algra A, Rinkel GJ, et al. High mean fasting glucose levels independently predict poor outcome and delayed cerebral ischaemia after aneurysmal subarachnoid haemorrhage. J Neurol Neurosurg Psychiatry (2008) 79:1382-5. doi:10.1136/jnnp.2007. 142034

83. Kruyt ND, Biessels GJ, De Haan RJ, Vermeulen M, Rinkel GJ, Coert B, et al. Hyperglycemia and clinical outcome in aneurysmal subarachnoid hemorrhage: a meta-analysis. Stroke (2009) 40:e424-30. doi:10.1161/STROKEAHA. 108.529974

84. Hanafy KA, Morgan Stuart R, Fernandez L, Schmidt JM, Claassen J, Lee K, et al. Cerebral inflammatory response and predictors of admission clinical grade after aneurysmal subarachnoid hemorrhage. J Clin Neurosci (2010) 17:22-5. doi:10.1016/j.jocn.2009.09.003

85. McGirt MJ, Woodworth GF, Ali M, Than KD, Tamargo RJ, Clatterbuck RE. Persistent perioperative hyperglycemia as an independent predictor of poor outcome after aneurysmal subarachnoid hemorrhage. J Neurosurg (2007) 107:1080-5. doi:10.3171/JNS-07/12/1080

86. Kruyt ND, Biessels GJ, Devries JH, Luitse MJ, Vermeulen M, Rinkel GJ, et al. Hyperglycemia in aneurysmal subarachnoid hemorrhage: a potentially modifiable risk factor for poor outcome. JCereb Blood Flow Metab (2010) 30:1577-87. doi:10.1038/jcbfm.2010.102

87. Bell DA, Strong AJ. Glucose/insulin infusions in the treatment of subarachnoid haemorrhage: a feasibility study. Br J Neurosurg (2005) 19:21-4. doi:10.1080/02688690500089423

88. Bilotta F, Spinelli A, Giovannini F, Doronzio A, Delfini R, Rosa G. The effect of intensive insulin therapy on infection rate, vasospasm, neurologic outcome, and mortality in neurointensive care unit after intracranial aneurysm clipping in patients with acute subarachnoid hemorrhage: a randomized prospective pilot trial. J Neurosurg Anesthesiol (2007) 19:156-60. doi:10.1097/ANA. 0b013e3180338e 69

89. Latorre JG, Chou SH, Nogueira RG, Singhal AB, Carter BS, Ogilvy CS, et al. Effective glycemic control with aggressive hyperglycemia management is associated with improved outcome in aneurysmal subarachnoid hemorrhage. Stroke (2009) 40:1644-52. doi:10.1161/STROKEAHA.108.535534

90. Schlenk F, Vajkoczy P, Sarrafzadeh A. Inpatient hyperglycemia following aneurysmal subarachnoid hemorrhage: relation to cerebral metabolism and outcome. Neurocrit Care (2009) 11:56-63. doi:10.1007/ s12028-009-9222-z

91. Thiele RH, Pouratian N, Zuo Z, Scalzo DC, Dobbs HA, Dumont AS, et al. Strict glucose control does not affect mortality after aneurysmal subarachnoid hemorrhage. Anesthesiology (2009) 110:603-10. doi:10.1097/ALN. 0b013e318198006a

92. Naidech AM, Levasseur K, Liebling S, Garg RK, Shapiro M, Ault ML, et al. Moderate hypoglycemia is associated with vasospasm, cerebral infarction, and 3-month disability after subarachnoid hemorrhage. Neurocrit Care (2010) 12:181-7. doi:10.1007/s12028-009-9311-z
93. Schlenk F, Graetz D, Nagel A, Schmidt M, Sarrafzadeh AS. Insulin-related decrease in cerebral glucose despite normoglycemia in aneurysmal subarachnoid hemorrhage. Crit Care (2008) 12:R9. doi:10.1186/cc6776

94. Schmidt JM, Claassen J, Ko SB, Lantigua H, Presciutti M, Lee K, et al. Nutritional support and brain tissue glucose metabolism in poor-grade $\mathrm{SAH}$ : a retrospective observational study. Crit Care (2012) 16:R15. doi:10.1186/cc11160

95. Ghajar J. Traumatic brain injury. Lancet (2000) 356:923-9. doi:10.1016/S01406736(00)02689-1

96. Morganti-Kossmann MC, Rancan M, Otto VI, Stahel PF, Kossmann T. Role of cerebral inflammation after traumatic brain injury: a revisited concept. Shock (2001) 16:165-77. doi:10.1097/00024382-200116030-00001

97. Hutchinson PJ. Microdialysis in traumatic brain injury - methodology and pathophysiology. Acta Neurochir Suppl (2005) 95:441-5. doi:10.1007/3-21132318-X_91

98. Andersen BJ, Marmarou A. Post-traumatic selective stimulation of glycolysis. Brain Res (1992) 585:184-9. doi:10.1016/0006-8993(92)91205-S

99. Bergsneider M, Hovda DA, Shalmon E, Kelly DF, Vespa PM, Martin NA, et al. Cerebral hyperglycolysis following severe traumatic brain injury in humans: a positron emission tomography study. J Neurosurg (1997) 86:241-51. doi:10.3171/jns.1997.86.2.0241

100. Oddo M, Schmidt JM, Carrera E, Badjatia N, Connolly ES, Presciutti M, et al. Impact of tight glycemic control on cerebral glucose metabolism after severe brain injury: a microdialysis study. Crit Care Med (2008) 36:3233-8. doi:10.1097/CCM.0b013e31818f4026

101. Goodman JC, Valadka AB, Gopinath SP, Uzura M, Robertson CS. Extracellular lactate and glucose alterations in the brain after head injury measured by microdialysis. Crit Care Med (1999) 27:1965-73. doi:10.1097/00003246199909000-00041

102. Vespa PM, McArthur D, O’Phelan K, Glenn T, Etchepare M, Kelly D, et al. Persistently low extracellular glucose correlates with poor outcome 6 months after human traumatic brain injury despite a lack of increased lactate: a microdialysis study. J Cereb Blood Flow Metab (2003) 23:865-77. doi:10.1097/01.WCB. 0000076701.45782.EF

103. Diaz-Parejo P, Stahl N, Xu W, Reinstrup P, Ungerstedt U, Nordstrom CH. Cerebral energy metabolism during transient hyperglycemia in patients with severe brain trauma. Intensive Care Med (2003) 29:544-50. doi:10.1007/s00134-0031669-3

104. Timofeev I, Carpenter KL, Nortje J, Al-Rawi PG, O’Connell MT, Czosnyka $\mathrm{M}$, et al. Cerebral extracellular chemistry and outcome following traumatic brain injury: a microdialysis study of 223 patients. Brain (2011) 134:484-94. doi:10.1093/brain/awq353

105. Magnoni S, Tedesco C, Carbonara M, Pluderi M, Colombo A, Stocchetti N. Relationship between systemic glucose and cerebral glucose is preserved in patients with severe traumatic brain injury, but glucose delivery to the brain may become limited when oxidative metabolism is impaired: implications for glycemic control. Crit Care Med (2012) 40:1785-91. doi:10.1097/CCM. 0b013e318246bd45

106. Rostami E, Bellander BM. Monitoring of glucose in brain, adipose tissue, and peripheral blood in patients with traumatic brain injury: a microdialysis study. J Diabetes Sci Technol (2011) 5:596-604. doi:10.1177/193229681100500314

107. Young B, Ott L, Dempsey R, Haack D, Tibbs P. Relationship between admission hyperglycemia and neurologic outcome of severely brain-injured patients. Ann Surg (1989) 210:466-72; discussion 472-3. doi:10.1097/00000658-19891000000007

108. Lam AM, Winn HR, Cullen BF, Sundling N. Hyperglycemia and neurological outcome in patients with head injury. J Neurosurg (1991) 75:545-51. doi:10.3171/jns.1991.75.4.0545

109. Rovlias A, Kotsou S. The influence of hyperglycemia on neurological outcome in patients with severe head injury. Neurosurgery (2000) 46:335-42; discussion 342-3. doi:10.1097/00006123-200002000-00015

110. Jeremitsky E, Omert LA, Dunham CM, Wilberger J, Rodriguez A. The impact of hyperglycemia on patients with severe brain injury. J Trauma (2005) 58:47-50. doi:10.1097/01.TA.0000135158.42242.B1

111. Salim A, Hadjizacharia P, Dubose J, Brown C, Inaba K, Chan LS, et al. Persistent hyperglycemia in severe traumatic brain injury: an independent predictor of outcome. Am Surg (2009) 75:25-9.

112. Vespa P, Boonyaputthikul R, McArthur DL, Miller C, Etchepare M, Bergsneider $\mathrm{M}$, et al. Intensive insulin therapy reduces microdialysis glucose values 
without altering glucose utilization or improving the lactate/pyruvate ratio after traumatic brain injury. Crit Care Med (2006) 34:850-6. doi:10.1097/01. CCM.0000201875.12245.6F

113. Meier R, Bechir M, Ludwig S, Sommerfeld J, Keel M, Steiger P, et al. Differential temporal profile of lowered blood glucose levels ( 3.5 to $6.5 \mathrm{mmol} / \mathrm{l}$ versus 5 to $8 \mathrm{mmol} / \mathrm{l}$ ) in patients with severe traumatic brain injury. Crit Care (2008) 12:R98. doi:10.1186/cc6974

114. Bilotta F, Caramia R, Cernak I, Paoloni FP, Doronzio A, Cuzzone V, et al. Intensive insulin therapy after severe traumatic brain injury: a randomized clinical trial. Neurocrit Care (2008) 9:159-66. doi:10.1007/s12028-008-9084-9

115. Arabi YM, Dabbagh OC, Tamim HM, Al-Shimemeri AA, Memish ZA, Haddad $\mathrm{SH}$, et al. Intensive versus conventional insulin therapy: a randomized controlled trial in medical and surgical critically ill patients. Crit Care Med (2008) 36:3190-7. doi:10.1097/CCM.0b013e31818f21aa

116. Marion DW. Optimum serum glucose levels for patients with severe traumatic brain injury. F1000 Med Rep (2009) 1:42. doi:10.3410/M1-42
Conflict of Interest Statement: The author declares that the research was conducted in the absence of any commercial or financial relationships that could be construed as a potential conflict of interest.

Received: 01 April 2014; paper pending published: 23 April 2014; accepted: 23 May 2014; published online: 06 June 2014.

Citation: Rostami E (2014) Glucose and the injured brain-monitored in the neurointensive care unit. Front. Neurol. 5:91. doi: 10.3389/fneur.2014.00091

This article was submitted to Neurotrauma, a section of the journal Frontiers in Neurology.

Copyright (C) 2014 Rostami. This is an open-access article distributed under the terms of the Creative Commons Attribution License (CC BY). The use, distribution or reproduction in other forums is permitted, provided the original author(s) or licensor are credited and that the original publication in this journal is cited, in accordance with accepted academic practice. No use, distribution or reproduction is permitted which does not comply with these terms. 